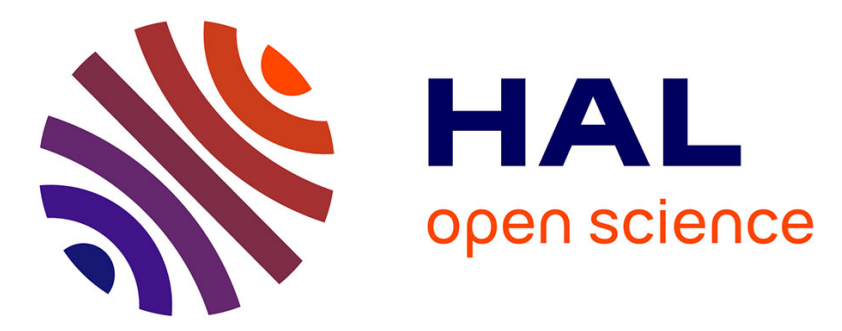

\title{
Molecular dynamics simulations for drug dosage form development: thermal and solubility characteristics for hot melt extrusion.
}

Martin Maus, Karl Gerhard Wagner, Gerhard Zifferer, Andreas Kornherr

\section{- To cite this version:}

Martin Maus, Karl Gerhard Wagner, Gerhard Zifferer, Andreas Kornherr. Molecular dynamics simulations for drug dosage form development: thermal and solubility characteristics for hot melt extrusion.. Molecular Simulation, 2008, 34 (10-15), pp.1197-1207. 10.1080/08927020802411695 . hal-00515056

\author{
HAL Id: hal-00515056 \\ https://hal.science/hal-00515056
}

Submitted on 4 Sep 2010

HAL is a multi-disciplinary open access archive for the deposit and dissemination of scientific research documents, whether they are published or not. The documents may come from teaching and research institutions in France or abroad, or from public or private research centers.
L'archive ouverte pluridisciplinaire HAL, est destinée au dépôt et à la diffusion de documents scientifiques de niveau recherche, publiés ou non, émanant des établissements d'enseignement et de recherche français ou étrangers, des laboratoires publics ou privés. 


\section{Molecular Simulation}

Journal of

Experimental Nanoscience

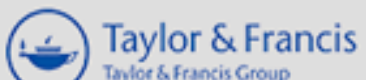

Taylor \& Francis Group

\section{Molecular dynamics simulations for drug dosage form development: thermal and solubility characteristics for hot melt extrusion.}

\begin{tabular}{|c|c|}
\hline Journal: & Molecular Simulation/Journal of Experimental Nanoscience \\
\hline Manuscript ID: & GMOS-2008-0017.R1 \\
\hline Journal: & Molecular Simulation \\
\hline $\begin{array}{r}\text { Date Submitted by the } \\
\text { Author: }\end{array}$ & 31-Mar-2008 \\
\hline Complete List of Authors: & $\begin{array}{l}\text { Maus, Martin; Boehringer Ingelheim Pharma GmbH \& Co KG, } \\
\text { Quality Operations } \\
\text { Wagner, Karl; Boehringer Ingelheim Pharma GmbH \& Co KG, } \\
\text { Pharmaceutical research and development } \\
\text { Zifferer, Gerhard; University of Vienna, Institute of Physical } \\
\text { Chemistry } \\
\text { Kornherr, Andreas; Mondi Business Paper Services AG }\end{array}$ \\
\hline Keywords: & drug dosage form, glass transition, plasticizer, polymer, solubility \\
\hline
\end{tabular}

\section{SCHOLARONE ${ }^{m}$ \\ Manuscripts}




\begin{abstract}
Properties of pharmaceutical drug polymer mixtures like miscibility, stability and drug release are determined by the interactions of active pharmaceutical ingredients (APIs) and excipients (e.g. plasticizers) with functional polymers. Molecular dynamics simulations (Materials Studio, compass force field) are used to predict the principal behaviour of such drug products, especially miscibility and glass transition temperature $\left(T_{\mathrm{g}}\right)$. Different mixtures containing APIs (theophylline or ibuprofen) and water soluble (triethyl citrate) or water insoluble plasticizer (acetyltributyl citrate or dibutyl sebacate) dissolved/dispersed in a cationic polymethacrylate (Eudragit ${ }^{\circledR}$ RS) were studied. Force field based calculations of the cohesive energy densities of single constituents led to a qualitative approach according to Hanson describing the solid state of the mixture while further calculations on the basis of the theory of free energy of mixing facilitated a semi quantitative prediction. In case of miscibility also calculation of $T_{\mathrm{g}}$ was possible via modelling specific volumes of amorphous cells at various temperatures. The simulated data correlated well with the experimental data obtained from differential scanning calorimetry of drug products processed via hotmelt extrusion. Accordingly, the described method facilitates a good estimate of pharmaceutical polymer drug mixtures thus decreasing product development time as well as the consumption of active ingredients.
\end{abstract}

Keywords: drug dosage form; glass transition; plasticizer; polymer; solubility

*Corresponding author. Email: martin.maus@boehringer-ingelheim.com 
Materials Studio special issue

FULL PAPER

\title{
Molecular dynamics simulations for drug dosage form development: thermal and solubility characteristics for hot melt extrusion.
}

\begin{abstract}
Properties of pharmaceutical drug polymer mixtures like miscibility, stability and drug release are determined by the interactions of active pharmaceutical ingredients (APIs) and excipients (e.g. plasticizers) with functional polymers. Molecular dynamics simulations (Materials Studio, compass force field) are used to predict the principal behaviour of such drug products, especially miscibility and glass transition temperature $\left(T_{\mathrm{g}}\right)$. Different mixtures containing APIs (theophylline or ibuprofen) and water soluble (triethyl citrate) or water insoluble plasticizer (acetyltributyl citrate or dibutyl sebacate) dissolved/dispersed in a cationic polymethacrylate (Eudragit ${ }^{\circledR}$ RS) were studied. Force field based calculations of the cohesive energy densities of single constituents led to a qualitative approach according to Hanson describing the solid state of the mixture while further calculations on the basis of the theory of free energy of mixing facilitated a semi quantitative prediction. In case of miscibility also calculation of $T_{\mathrm{g}}$ was possible via modelling specific volumes of amorphous cells at various temperatures. The simulated data correlated well with the experimental data obtained from differential scanning calorimetry of drug products processed via hotmelt extrusion. Accordingly, the described method facilitates a good estimate of pharmaceutical polymer drug mixtures thus decreasing product development time as well as the consumption of active ingredients.
\end{abstract}

Keywords: drug dosage form; glass transition; plasticizer; polymer; solubility 


\section{Introduction}

In the last decade the use of molecular dynamics (MD) simulations has become more and more familiar to pharmaceutical developers, e.g. by checking on polymorphisms [1,2] and calculating properties of host-guest complexes [3, 4]. Furthermore, MD simulations can assist dosage form development by predicting valuable physico-chemical properties like viscosity of solutions [5], diffusivity [6] and water adsorption [7]. However, the above-mentioned parameters are often limited to "small" systems either related to the molecular weight of the drug compound and/or the excipient employed. The aim of our study is, therefore, to find in silico test models using MD methods for polymers, excipients, drugs and mixtures thereof exceeding standard MD applications in complexity and hence, facilitates preformulation even at a stage where drug compound or polymer are in an in silico stage of development. Also the risk of unexpected physical or chemical incompatibilities (e.g. immiscibility) during the formulation process, which is time consuming and expensive [8], might be decreased. Fortunately, molecular simulation offers the possibility to calculate many relevant physical properties of the desired excipient and drug molecules as well as of the polymer without the need of costly experiments.

In this respect, the in silico prediction of the thermodynamical mixing behaviour of different polymer-drug/excipient mixtures is of central interest. A common approach to cope with this problem is the calculation of the solubility parameters according to Hildebrand or Hansen [912], which is standard in the development of polymer mixtures [13]. The use of highly developed force fields as the basis of any MD simulation software enables the calculation of solubility parameters with an accuracy comparable to those measured experimentally by inverse gas chromatography [14] and an increasing number of other statistical quantitative property relationship (SQPR) between simulated and experimental values are established [15$18]$.

Focusing on polymer plasticizer blends, the glass transition temperature $\left(T_{\mathrm{g}}\right)$ is an important property in order to predict the formation of a solid solution. Homogenous polymer plasticizer blends undergo a second-order like phase transition at this temperature [19], passing from the rubbery to a glassy state with $T_{\mathrm{g}}$ decreasing with increasing plasticizer concentrations [20, 21]. Throughout the literature several approaches to determine the glass transition temperature of polymers via computer simulations are reported based on the change of various physical properties at $T_{\mathrm{g}}$. One common approach is to determine the kink in a graph of the specific volume $v$ versus temperature $T[14,19,22-27]$ originating from the change of the thermal 
expansion coefficient. Other approaches also use the increase of the potential energy [23-26] at $T_{\mathrm{g}}$ or the temperature dependence of the mean square displacement of polymer chains below and above $T_{\mathrm{g}}[26,28]$. Normally, all these methods lead to a good prediction of $T_{\mathrm{g}}$ values for pure polymers.

Simulations of pharmaceutical relevant mixtures of polymer/excipient/drug blends however, are scarce. Momany et al [25] investigated the dependence of $T_{\mathrm{g}}$ of maltodecaose on its hydration (water is known to act as a plasticizer for carbohydrates) and Yoshioka et al. [29] probed $T_{\mathrm{g}}$ values of freeze-dried dextran cakes. Quite recently, we studied the $T_{\mathrm{g}}$ dependence of an ammonio methacrylate copolymer (Eudragit ${ }^{\circledR}$ RS) as a function of its triethyl citrate (TEC) content [27] which was in good agreement when compared to experimental data.

In this follow-up study we want to examine the miscibility and the impact on the drug dosage form in respect of $T_{\mathrm{g}}$ from systems including Eudragit ${ }^{\circledR} \mathrm{RS}$ (a cationic ammonio methacrylate copolymer; type B), three common plasticizers (triethyl citrate, acetyltributyl citrate, and dibutyl sebacate) and two active ingredients: ibuprofen (likely plasticizing impact on Eudragit RS [30]) and theophylline (unlikely plasticizing influence on Eudragit RS [31, 32-34]).

The aim is to assist the developer in the two pivotal development questions of a hot melt extruded dosage form:

1. What is the best polymer plasticizer mixture to obtain the lowest possible processing temperature for the extrusion process? - A problem, which is, of course, closely linked to a low value for $T_{\mathrm{g}}$.

2. What is the extend of the drug compound's solubility in the respective polymer plasticizer blend? - The solubility should be rather high for the purpose of forming a solid solution to improve API solubility. - And in contrast should be very low in case a drug dispersion is intended to be formed to extend the API release from the polymer matrix.

In order to compare the simulated values with the hot-melt extrusion process the feasible blends are produced through hot melt extrusion, performed on a lab scale ram extruder. Employing Eudragit ${ }^{\circledR}$ RS as a thermal polymer which is known to form multiple unit controlled release matrix particles [20,34-36] the purpose in respect of question two was to distinguish a system of low solubility for the drug compound.

\section{Materials and methods}

All different substances used in this study are visualized in Figure 1 (all chemical structures are conformational not optimized due to a better visibility). 


\section{Materials}

Triethyl citrate (TEC) was purchased from Merck KGaA (Darmstadt, Germany). The other substances were kindly donated by various manufactures: Eudragit ${ }^{\circledR}$ RS 100 by Röhm GmbH (Darmstadt, Germany), acetyltributyl citrate (ATBC) by Jungbunzlauer Ladenburg GmbH (Ladenburg, Germany), dibutyl sebacate (DBS) by Morflex Inc. (Greensboro, USA), Ibuprofen by Knoll Pharmaceuticals (Nottingham, UK), and theophylline anhydrous powder by BASF AG (Ludwigshafen, Germany).

\section{Numerical methods}

\section{a) Calculation of solubility parameters}

In order to calculate the solubility of both plasticizer and drug molecules within a given

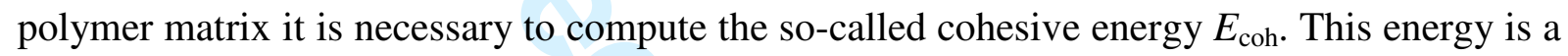
measure of the intermolecular forces (both electrostatic as well as dispersive) acting between the molecules of a specific substance. Accordingly, $E_{\mathrm{coh}}$ corresponds to the experimental value of the internal heat of vaporisation $\Delta H_{\text {vap }}$ (with $R$ being the real gas constant) [10].

$$
E_{c o h}=\Delta H_{\text {vap }}-R \cdot T \quad(\text { Equation } 1)
$$

In a computer simulation the energy (and force) between different molecules is directly accessible from the force field. Therefore, it is possible to compute $E_{\text {coh }}$ directly and to transform it into the Hildebrand solubility parameter $\delta[10]$ according to:

$$
\delta=\sqrt{E_{\text {coh }} / V} \quad \text { (Equation 2) }
$$

with $V$ being the volume of the phase of which $E_{\text {coh }}$ is calculated.

For this numerical procedure cubic simulation boxes (with periodic boundary conditions in all directions) containing either 4 polymer chains consisting of 62 monomer units each or 60 plasticizer/drug molecules are constructed. Dependent on the type of plasticizer, the cubic box size has a side length of ca. $4 \mathrm{~nm}$ (Figure 2). For each type of molecule 10 independently generated simulation boxes are minimized with respect to the total energy. Out of those, the lowest energy system is further relaxed for 2 ns under NPT conditions at ambient conditions, i.e. at constant pressure $\left(10^{5} \mathrm{~Pa}\right)$ and constant temperature $(298 \mathrm{~K})$ to obtain a well relaxed start structure with the correct density using the Anderson thermostat and barostat [37] with a time step of 1 fs. Afterwards, a 200 ps run at constant temperature and constant volume (NVT conditions) is carried out -100 ps for equilibration and 100 ps for data sampling. Thus, the 
cohesive energy is averaged over this latter period and the according cohesive energy density $E_{\text {coh }} / V$ is calculated by dividing it through the volume of the simulation cell.

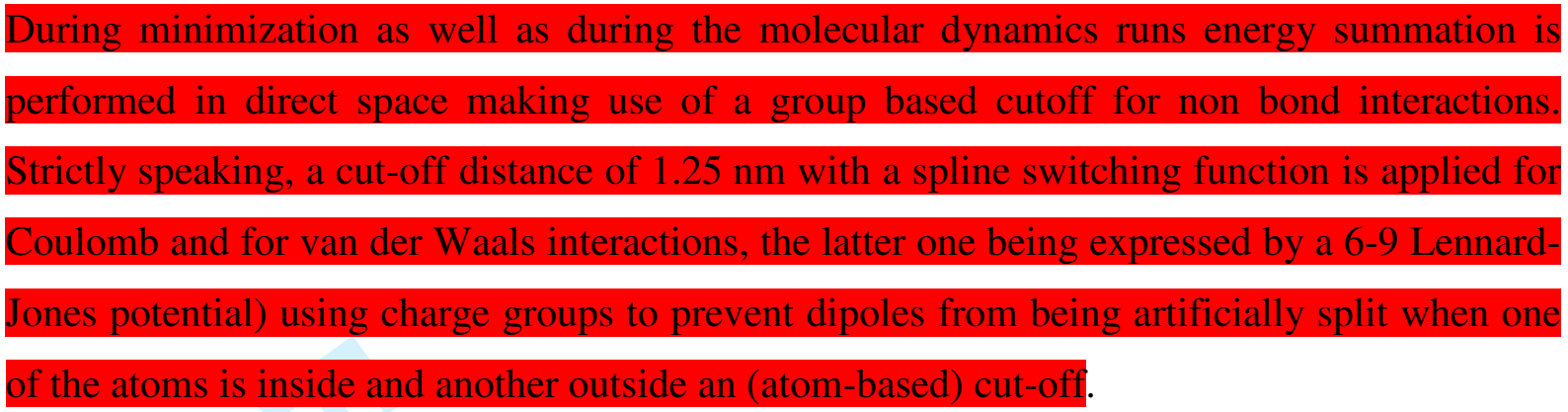

For the whole simulation procedure the software package MS Modeling 3.0 (from Accelrys Inc.) was applied using the Amorphous Cell tool for construction of the amorphous phase and Discover as the molecular dynamics code. Atomic charges and interactions between atoms and molecules were accounted for by use of the COMPASS force field [38-41], which is highly optimized for the simulation of condensed phases.

\section{b) Determination of the specific volume as a function of temperature}

The numerical procedure is very similar to the method described in the previous chapter (cf. also ref. [27]). However, now several independent starting structures (generally 3-5, to average the obtained final specific volumes to decrease scatter) of the corresponding system are chosen and relaxed for $2 \mathrm{~ns}$ under NPT conditions at a temperature approximately $100 \mathrm{~K}$ higher than the supposed glass transition temperature. Afterwards, a "cooling process" is initiated by lowering the temperature stepwise by $10 \mathrm{~K}$ until a temperature $\approx 100 \mathrm{~K}$ lower than $T_{g}$ is reached. At each temperature $200 \mathrm{ps}$ NPT ensemble dynamics is carried out $-150 \mathrm{ps}$ for equilibration and $50 \mathrm{ps}$ for data sampling (i.e. averaging the specific volume $v$ over this period) using the final configuration of this run as the starting structure for dynamics at the next (10 K lower) temperature.

\section{Experimental methods}

\section{Hot melt extrusion}

According to the aim of the study, the mixtures of the polymer and its plasticizing agents were produced by hot-melt extrusion at $140^{\circ} \mathrm{C}$. The ram extruder, assembled by an in house precision mechanic shop, consists of a massive brass cylinder with a 1200 Watt heat source connected to a self-adapting power controller KS40-1 (PMA Prozess- und MaschinenAutomation GmbH, Kassel, Germany) equipped with a PT-100 sensor. The barrel diameter is $10.0 \mathrm{~mm}$ and the length $280 \mathrm{~mm}$. By connecting a material testing machine DO-FB0.5TS 


\section{Results and Discussion}

This section is divided into three parts:

- First, we will discuss the determination of solubility parameters in order to predict and to explain polymer-plasticizer/drugs miscibility. It is very important-both from a theoretical as well as from an experimental point of view - to ensure that two components are able to build a stable, homogenous mixture.

- Second, we will apply this knowledge to decide which of the possible polymerplasticizer/drugs systems are suitable for a calculation of $T_{\mathrm{g}}$.

- In the third part, the calculated $T_{\mathrm{g}}$ values will be compared to experimental values.

\section{I) Numerical determination of solubility properties}

A computational method in combination with a suitable force field provides an advantage in contrast to the commonly used group-number systems [9, 43] for calculating the solubility 
parameters according to Hildebrand [10] and Hansen [11]. Recent comparisons of simulated solubility parameters with solubility parameters measured using reverse gas chromatography and other experimental methods [44] proved the accurateness of the simulated values.

All plasticizers used in this study are commonly used for the application of polymer coatings as well as for matrix systems [31-33, 45-47]. Triethylcitrate (TEC) is the standard plasticizer for Eudragit RS with a maximum water solubility of 5 percent, underlining its hydrophilic character. Acetyltributyl citrate (ATBC) was chosen due to its structural similarity compared to TEC, but with an increased lipophilic character. The third plasticizer, the double butylated decandicarboxy acid (DBS) has a similar lipophilic character as ATBC but the different molecular structure allows for an additional testing of our computational method.

Ibuprofen (IBU) as a nonsteroideal anti-inflammatory is reported to have plasticizing properties in combination with Eudragit ${ }^{\circledR}$ RS [30] thus representing a model drug with severe interactions with the polymer matrix. Its aromatic molecular structure presents a further change in the geometry as well as in the hydrophilic-lipophilic character. In contrast, the antiasthmatic methylxanthine theophylline has proven its inertness within formulations containing Eudragit RS [31-34] and was therefore chosen as the second active ingredient in our study.

The physical states of the substances modelled differ at 298.15 K: DSC measurements (see also section IIIb ) show that polymer Eudragit ${ }^{\circledR}$ RS is amorphous without crystalline sections. In contrast, the plasticizers TEC, ATBC, and DBS are fluids. Furthermore, the drugs ibuprofen and theophylline are crystalline with ibuprofen melting within the hot-melt extrusion process while theophylline stays solid. These differences were taken into account for the calculation of the solubility parameters: using crystallographic data from the Cambridge Structural Database it was possible to calculate both the solubility parameters of these crystalline drugs as well as the solubility parameters of the corresponding amorphous (i.e. molten) state.

\section{a) Hildebrand solubility parameters}

The Hildebrand solubility parameters calculated within the MD simulation are presented in Table 1. As expected, crystalline drugs have the highest cohesive energy density with the Hildebrand parameter $\delta$, see Equation (2), reading $31.64\left(\mathrm{~J} / \mathrm{cm}^{3}\right)^{0.5}$ for ibuprofen and $51.43\left(\mathrm{~J} / \mathrm{cm}^{3}\right)^{0.5}$ for theophylline, respectively. In contrast, amorphous substances show a reduced energy density. This can easily be explained by the absence of the melting heat that has to be overcome for crystalline substances. With $\delta$ reading $17.43\left(\mathrm{~J} / \mathrm{cm}^{3}\right)^{0.5}$, the pure 
polymer has the lowest solubility parameter. The plasticizers and amorphous IBU are in the same range up to a maximum of $20.95\left(\mathrm{~J} / \mathrm{cm}^{3}\right)^{0.5}$ for IBU.

\section{b) Hansen solubility parameters}

Hansen [11] divided the Hildebrand solubility parameter $\delta$ into contributions from the nonpolar van der Waals dispersion forces $\delta_{\mathrm{d}}$, the polar (electrostatic) interactions $\delta_{\mathrm{p}}$, and the hydrogen bonding interactions $\delta_{\mathrm{h}}$

$$
\delta^{2}=\delta_{\mathrm{d}}^{2}+\delta_{\mathrm{p}}^{2}+\delta_{\mathrm{h}}^{2} \quad(\text { Equation } 3)
$$

In most modern force fields like COMPASS, however, hydrogen bonding interactions are incorporated in the polar interactions, therefore, discrimination between $\delta_{\mathrm{p}}$ and $\delta_{\mathrm{h}}$ can not be made. Accordingly, in our calculations these parameters are combined to $\delta_{\mathrm{e}}$

$$
\delta_{\mathrm{e}}=\sqrt{\delta_{\mathrm{p}}^{2}+\delta_{\mathrm{h}}^{2}} \quad(\text { Equation } 4)
$$

The Hansen solubility parameters that were calculated according Equation 4 are presented in Table 1. With $\delta_{\mathrm{d}}$ values of ca.17 to $19\left(\mathrm{~J} / \mathrm{cm}^{3}\right)^{0.5}$ all plasticizing molecules were within a narrow range, only the polymer seemed to have a reduced dispersive solubility parameter value reading $13.13\left(\mathrm{~J} / \mathrm{cm}^{3}\right)^{0.5}$. A better discrimination was possible by comparison of the different values of the electrostatic interaction parameter $\delta_{\mathrm{e}}$ : with a $\delta_{\mathrm{e}}$ value of $11.32\left(\mathrm{~J} / \mathrm{cm}^{3}\right)^{0.5}$ the pure polymer was in the same range, compared to amorphous ibuprofen $\left(11.89\left(\mathrm{~J} / \mathrm{cm}^{3}\right)^{0.5}\right)$ and the hydrophilic plasticizer TEC $\left(8.62\left(\mathrm{~J} / \mathrm{cm}^{3}\right)^{0.5}\right)$, thus indicating an excellent miscibility. In contrast both, the value of DBS $\left(3.29\left(\mathrm{~J} / \mathrm{cm}^{3}\right)^{0.5}\right)$ and the value of ATBC $\left(4.57\left(\mathrm{~J} / \mathrm{cm}^{3}\right)^{0.5}\right)$ showed an extended lipophilic character.

Extremely high values however, can be observed when considering the crystalline state of the drugs theophylline and ibuprofen with $\delta_{\mathrm{e}}$ readings of $45.85\left(\mathrm{~J} / \mathrm{cm}^{3}\right)^{0.5}$ and $26.53\left(\mathrm{~J} / \mathrm{cm}^{3}\right)^{0.5}$, respectively. In addition, even the - only hypothetical - amorphous state of theophylline showed a $\delta_{\mathrm{e}}$ value of $16.99\left(\mathrm{~J} / \mathrm{cm}^{3}\right)^{0.5}$ and a $\delta_{\mathrm{d}}$ parameter of $\left(24.10\left(\mathrm{~J} / \mathrm{cm}^{3}\right)^{0.5}\right.$. Therefore, no miscibility of this drug with the polymer could be expected. For ease of comparison of the different $\delta_{\mathrm{e}}$ and $\delta_{\mathrm{d}}$ values, a graphical representation is given in Figure 3.

\section{c) Flory Huggins interaction parameter}

The qualitative considerations of the previous section regarding the solubility of plasticizers/drug/polymer blends can be transferred into a quantitative prediction of miscibility by calculation of the Flory Huggins interaction parameter $\chi$ [48] 


$$
\chi=\frac{V_{m 1} \cdot\left(\delta_{1}-\delta_{2}\right)^{2}}{R \cdot T} \quad(\text { Equation } 5)
$$

$V_{\mathrm{m} 1}=$ molar volume of plasticizing substance

$\delta_{1}=$ solubility parameter of plasticizer

$\delta_{2}=$ solubility parameter of polymer

$R=8.314472 \mathrm{~J} /(\mathrm{mol} \cdot \mathrm{K})$ (real gas constant)

$T=298.15 \mathrm{~K}$ (absolute temperature)

An interaction parameter of zero describes an ideal solute-solvent system, where the energetic interactions of two different molecules within a solution are equal to the interactions within the pure substance. The higher the value of $\chi$ the more dissimilar are the two substances and therefore, will not easily dissolve each other.

The calculation of this interaction parameter of different substances and the polymer displayed the differences as well as similarities of the studied blends (see Table 2). For all classic plasticizers the Flory Huggins parameter $\chi$ was equal to or less than 1.132 when mixed with the polymer. For the crystalline drugs ibuprofen and theophylline $\chi$ would read 56.6 and 15.5 , respectively, whereas the corresponding amorphous states show an extreme decrease in $\chi$ reading 1.1 and 7.9 .

\section{d) Gibbs free enthalpy change of mixing}

The Gibbs energy of mixing $\Delta G_{\mathrm{m}}$ [49] describes the overall thermodynamic benefit of generating a polymer-plasticizer mixture. Mixing of two substances only occurs in case of negative values of $\Delta G_{\mathrm{m}}$. As a molecular solution of the plasticizer in the polymer matrix is an indispensable requirement for its plasticizing properties the possibility to calculate the value of $\Delta G_{\mathrm{m}}$ prior to the specific experiment is extremely helpful in practice.

$$
\Delta G_{\mathrm{m}}=k \cdot T \cdot\left(\frac{N}{V_{m 1}} \cdot v_{1} \cdot \ln v_{1}+\frac{N}{V_{m 2}} \cdot v_{2} \cdot \ln v_{2}+\chi \cdot \frac{N}{V_{m 1}} \cdot v_{1} \cdot v_{2}\right) \quad \text { (Equation 6) }
$$

$k=1.38 \mathrm{E}-23 \mathrm{~J} / \mathrm{K}$ (Bolzmann constant)

$T=298.15 \mathrm{~K}$ (absolute temperature)

$N=6.02 \mathrm{E}+231 / \mathrm{mol}$ (Avogadro constant)

$V_{\mathrm{m} 1}=$ molar Volume of plasticizing substance

$V_{\mathrm{m} 2}=$ molar Volume of polymer chain 
$v_{1}=0.1$ (volume fraction of plasticizer)

$v_{2}=0.9$ (volume fraction of polymer)

In Table 2 the $\Delta G_{\mathrm{m}}$ values calculated according to Equation (6) for different polymerplasticizer systems with a typical value for the plasticizer volume fraction of $10 \%$ are presented. As expected from the solubility parameters these values are positive for the crystalline drugs and even for the hypothetical amorphous state of theophylline. Therefore, further simulations (and experiments) considering the plasticizing properties of theophylline made no sense.

\section{II) Simulation of plasticizing properties}

The glass transition temperatures of all substances that show a possible molecular miscibility with the polymer matrix were simulated. As described in the numerical section, a previously reported MD method [27] was applied.

\section{a) Different polymer/TEC solid state solutions}

The first check of our improved model (4 instead of 8 polymer chains, but with a doubled chain-length) for the MD simulations was a recalculation of $T_{\mathrm{g}}$ of the previously simulated [27] polymer-TEC systems. Again, a cooling of the new model of the pure polymer from $480 \mathrm{~K}$ to $250 \mathrm{~K}$ in $10 \mathrm{~K}$ steps showed a clearly visible kink in the specific volume $v$ vs. temperature $T$ diagram (Figure $4 \mathrm{a}$ ), thus indicating a second order like phase transition from the rubbery to the glassy state. The glass transition temperature $(354 \mathrm{~K})$ was indicated by the interception of two linear regression lines from the rubbery and the glassy phase.

Analogous to the previous work [27] mixed systems containing 4 long polymer chains plus 6 or 12 TEC molecules per simulation box were constructed and the corresponding $T_{\mathrm{g}}$ values were determined (see Figure $4 \mathrm{~b}$ and c): $332 \mathrm{~K}$ for the 6 TEC and $308 \mathrm{~K}$ for 12 TEC system. Accordingly, the improved new model for the MD simulation of the TEC containing Eudragit $^{\circledR}$ RS systems showed a nearly perfect linear correlation of a decreasing value of $T_{\mathrm{g}}$ at an increasing plasticizer concentration (see Figure 5).

Although, some deviation from experimental DSC data still occurred, the comparison with the previously reported [27] short-chain system (dotted line in Figure 5) clearly highlights the improvement of doubling the polymer chain length in the new model used in this work. 


\section{b) Further solid polymer-plasticizer solutions}

Due to the good reproducibility of calculated and experimental $T_{\mathrm{g}}$ values of the plasticizer TEC, the more lipophilic plasticizers ATBC and DBS as well as the model drug ibuprofen were tested also. Amorphous cells containing 4 polymer chains and 6 molecules of either ATBC, DBS, or ibuprofen were constructed and the corresponding $T_{\mathrm{g}}$ values were determined by analysing the kink in the $v$ vs. $T$ diagrams (Figure 6).

All data points within the simulated temperature range of ATBC were included for the subsequent analysis. Due to the distinct kink in the $v$ vs. $T$ graphs it was easy to separate them into two parts (a rubbery and a glassy part) and fitting them to a straight line by linear regression (Figure 6a). In contrast, data points of both DBS and ibuprofen showed a larger temperature interval where the second order phase transition seems to take place. This was indicated by larger deviations from the linear regression lines in the rubbery as well as in the glassy state. Accordingly, some values in this region without a clear defined physical state (rubbery or glassy) have been left out for analysis (see Figure 6b and 6c).

In Table 3 the calculated and via DSC measured glass transition temperatures of all simulated systems are presented. As expected, simulated $T_{\mathrm{g}}$ values were always higher than the experimental values due to the high cooling rate in a computer experiment (i.e. in an in silico experiment one could regard the system as being "shock frozen"). However, the discrepancies were only $4-11 \%$ thus indicating the reliability of the presented computational method.

\section{III) Experimental check of the plasticizing properties}

\section{a) Production of solid solutions using a hot-melt ram-extruder}

All physical mixtures were extruded at the conditions stated in the experimental section. By subsequently extruding the mixtures three times, enough shear was applied to achieve well distributed solid solutions of the plasticizers within the polymer matrix. A comparison of the development of the force effect during the extrusion cycles showed a reduction in the force effect at each step. This trend clearly indicated that the homogeneity increased through the multiple ram-extrusion. Furthermore, all three plasticizers, TEC, ATBC, and DBS, showed either extreme stickiness, or a too soft consistency of the extruded polymer strands at levels higher than $25.5 \%$. Therefore, a plasticizer fraction $w$ of $25.5 \%(\mathrm{~m} / \mathrm{m})$ indicated the endpoint in the application range.

The crystalline drug ibuprofen melts at $76^{\circ} \mathrm{C}$, so the applied extrusion temperature allowed the incorporation of molten drug into the polymer matrix. Therefore, ibuprofen could be 


\section{b) Thermal analysis of the extrudates}

The subsequent DSC measurements of the produced polymer-TEC, -ATBC, and -DBS extrudates, up to a weight percentage of $19 \%$, showed a clearly visible, strictly amorphous step when the heat flow was plotted against the reference temperature $T$. A representative DSC plot of the transition of the pure polymer as well as a polymer-TEC extrudate at $17 \%$ is shown in Figure 7.

As it was reported earlier for other polymer/plasticizer blends [27, 30, 34, 42, 45], the measured $T_{g}$ values of the extrudates exhibited a linear dependence on to the mass fraction $w$ of plasticizer in the melt. Furthermore, all the plasticizers studied in our work showed a good experimental solubility in the acrylic copolymer Eudragit ${ }^{\circledR}$ RS thus resulting in homogeneous solid solutions by the application of the ram-extruder.

However, as one could already mention within the qualitative comparison of the Hansen parameters in Table 1 and Figure 3, there exists a limit of solubility of plasticizers like DBS in the polymer matrix (at weight percentage of 19\%). This could be proven by DSC measurements of matrices containing $21.5 \%$ of DBS, a representative Plot is presented in Figure 8. In contrast to homogenous polymer/plasticizer blends where an amorphous step in the heat flow vs. temperature plot is visible, a dent-marking the melting point of the plasticizer DBS - occurs on the plot. Therefore, this mixture actually existed of two different, only mechanically mixed, phases: a polymer and a plasticizer phase.

Ibuprofen exhibited a similar behaviour like the three plasticizers: again, a linear correlation of the weight proportion of ibuprofen and the $T_{\mathrm{g}}$ of the matrix was found as it was also reported by Motonori Kidokoro et al. [34], its ability to plasticize Eudragit ${ }^{\circledR}$ RS was slightly lower, compared to the plasticizers.

In contrast, theophylline did neither influence the glass transition temperature of the pure polymer nor of the investigated polymer/plasticizer mixtures which is in good agreement with previous works [30, 34]. 


\section{Conclusion}

Our study shows that solubility properties of different polymer-plasticizer/drug blends can be calculated by the application of MD simulations using a proper force field. However, Hildebrand's parameter $\delta$ leads to an incomplete picture of the solubility property of a given system, e.g. polymer-DBS: although this lipophilic plasticizer exhibited nearly the same solubility parameter $\delta$ as the polymer (indicating a nearly ideal mixture) it showed an experimental solubility limit at higher plasticizer fractions. In contrast, solubility parameters according to Hansen deliver a more detailed picture by splitting $\delta$ in a dispersive $\delta_{\mathrm{d}}$ and an electrostatic $\delta_{\mathrm{e}}$ component: now, due to the large difference of $\delta_{\mathrm{e}}$ between the polymer and the plasticizer a solubility limit could be explained at least qualitatively.

However, a final decision whether a substance has the theoretical potential to build a stable blend with the polymer or not can only be made by calculating the Gibbs energy. As can be seen in Table 2 only TEC, ATBC, DBS and amorphous ibuprofen showed a theoretical miscibility with the polymer. This was also proven by experiments studying hot-melt extrudates.

Based on these solubility calculations only miscible polymer-plasticizer/drug systems were further investigated with respect to their plasticizing properties. The correlation of the simulated $T_{\mathrm{g}}$ values with experimental ones reflects the different solubility behaviour of the plasticizers studied: less miscible plasticizers like DBS and ATBC show a higher deviation from the experimental $T_{\mathrm{g}}$ values while the good soluble plasticizer TEC as well as the amorphous drug ibuprofen exhibit markedly less differences. Accordingly, it seems as if the modelling of the glass transition of polymer-like plasticizers results in a better agreement with experimental values compared to the less miscible substances. With the maximum discrepancies between simulated and experimental values being not more than $11 \%$ in the worst case the validity of our improved computer model is demonstrated. Thus it is possible to make predictions of the glass transition temperature of these systems with high precision.

As a concluding remark it can be stated, that our method gives pharmacists a valuable recipe how to treat unknown polymer-plasticizer/drug systems with respect to their mixing and plasticizing properties. The benefit of the presented method is a direct reduction of time expenditure and costs, in relation to the present trial and error principle in dosage form development. 


\section{References}

[1] F.J.J. Leusen, S. Wilke, P. Verwer and G. E. Engel, Computational approaches to crystal structure and polymorph prediction, in Implications of Molecular and Materials Structure for New Technologies, NATO Science Series E 360 (1999), pp. 303-314.

[2] P. Verwer and F.J.J. Leusen, Computer Simulation to Predict Possible Crystal Polymorphs, Reviews in Computational Chemistry 12 (1998), pp. 327-365.

[3] L. Lawtrakul, H. Viernstein and K. Wolschann, Molecular Dynamics Simulations of BCyclodextrin in Aqueous Solution, I. J. Pharm. 256 (2003), pp. 33-41.

[4] H. Viernstein, P. Weiss-Greiler and K. Wolschann, Quantitative Determination of Water in y-Cyclodextrin by Near-Infrared Spectroscopy, Pharm. Ind. 67 (2005), pp. 122-125.

[5] K. Zhang and C.W. Manke, Simulation of polymer solutions by dissipative particle dynamics, Molecular Simulation 25(3-4) (2000), pp. 157-166.

[6] M. Meunier, Diffusion coefficients of small gas molecules in amorphous cis-1,4polybutadiene estimated by molecular dynamics simulations, J. Chem. Phys. 123,13 (2005), pp. 134906.

[7] Y. Aray, M. Marquez, J. Rodriguez, S. Coll, Y. Simo'n-Manso, C. Gonzalez and D.A. Weitz, Electrostatics for Exploring the Nature of Water Adsorption on the Laponite Sheets' Surface, J. Phys. Chem. B 107 (2003), pp. 8946-8952.

[8] M. Swenson, M. Languell and J. Golden, Modeling and Simulation: The Return on Investment in Materials Science, IDC White Paper (2004), pp. 1-24.

[9] A. Forster, J. Hempenstall I. Tucker and T Rades, Selection of excipients for melt extrusion with two poorly water-soluble drugs by solubility parameter calculation and thermal analysis, Int. J. Pharm. 226,1-2 (2001), pp. 147-16.

[10] J.H. Hildebrand, Solubility. J. Am. Chem. Soc. 38,8 (1916), pp. 1452-1473.

[11] C.M. Hansen, Hansen solubility parameters, A user's handbook, CRC Press, Boca Raton, 2000.

[12] J. Burke, Solubility Parameters: Theory and Application, in AIC Book and Paper Group Annual 3 (1984), pp. 13-58. Available at http://aic.stanford.edu/sg/bpg/annual/v03/bp03-04.html (accessed 06/27/2006).

[13] P. Choi, Molecular dynamics studies of the thermodynamics of HDPE/butene-based LLDPE blends, Polymer 41,24 (2000), pp. 8741-8747.

[14] J. Han, R.H. Gee and R.H. Boyd, Glass Transition Temperatures of Polymers from Molecular Dynamics Simulations, Macromolecules 27,26 (1994), pp. 7781-7784. 
[15] L. Zhao and P. Choi, Study of the correctness of the solubility parameters obtained from indirect methods by molecular dynamics simulation, Polymer 45,4 (2004), pp. 13491356.

[16] M. Belmares, M. Blanco, W.A. Goddard III, R.B. Ross, G. Caldwell, S.H. Chou, J. Pham, P.M. Olofson and C. Thomas, Hildebrand and Hansen Solubility Parameters from molecular dynamics with Applications to Electronic Nose Polymer Sensors, J. Comput. Chem. 25,15 (2004), pp. 1814-1826.

[17] P. Choi, T. A. Kavassalis and A. Rudin, Estimation of the three-dimensional solubility parameters of alkyl phenol ethoxylates using molecular dynamics, J Colloid Interface Sci. 150,2 (1992), pp. 386-393.

[18] T.A. Kavassalis, P. Choi and A. Rudin, The calculation of 3D solubility parameters using molecular models, Mol. Simul. 11,2-4 (1993), pp. 229-241.

[19] H. Yang, L. Ze-Sheng, H. Qian, Y. Yang, X. Zhang and C. Sun, Molecular dynamics simulation studies of binary blend miscibility of poly(3-hydroxybutyrate) and poly(ethylene oxide), Polymer 45,2 (2004), pp. 453-457.

[20] Y. Zhu, N.H. Shah, A.W. Malick, M.H. Infeld and J.W. McGinity, Solid-state plasticization of an acrylic polymer with chlorpheniramine maleate and triethyl citrate, Int. J. Pharm. 241,2 (2002), pp. 301-310.

[21] R. Gruetzmann and K.G. Wagner, Quantification of the leaching of triethyl citrate/polysorbate 80 mixtures from Eudragit RS films by differential scanning calorimetry, Eur. J. Pharm. Biopharm. 60,1 (2005), pp. 159-162.

[22] C.F. Fan, T. Cagin, W. Shi and K.A. Smith, Local chain dynamics of a model polycarbonate near glass transition temperature. A molecular dynamics simulation, Macomol. Therory Simul. 6,1 (1997), pp. 83-102.

[23] K. Yu, Z. Li and J. Sun, Polymer structures and glass transition: a molecular dynamics simulation study, Macromol. Theory Simul. 10,6 (2001), pp. 624-633.

[24] J.R. Fried and P. Ren, Molecular simulation of the glass transition of polyphosphazenes, Comput. Theor. Polym. Sci. 9,2 (1999), pp. 111-116.

[25] F.A. Momany and J.L. Willett, Molecular Dynamics Calculations on Amylose fragments. I. Glass Transition Temperatures of Maltodecaose at 1, 5, 10 and 15.8\% Hydration, Biopolymers 63,2 (2002), pp. 99-110.

[26] R. Roe, MD Simulation Study of Glass Transition and Short Time Dynamics in Polymer Liquids. In Lucien Monnerie, U.W. Suter (eds.) Advances in Polymer Science 116, Springer, Berlin Heidelberg, 1994, pp. 111-144. 
[27] K.G. Wagner, M. Maus, A. Kornherr and G. Zifferer, Glass transition temperature of a cationic polymethacrylate dependent on the plasticizer content - Simulation vs. experiment, Chem. Phys. Lett. 406 (2005), pp. 90-94.

[28] Y. Tamai, A practical method to determine glass transition temperature in molecular dynamics simulation of mixed ionic glasses, Chem. Phys. Lett. 351,1-2 (2002), pp. 99104.

[29] S. Yoshioka, Y. Aso and S. Kojima, Prediction of Glass Transition Temperature of Freeze-Dried Formulations by Molecular Dynamics Simulation, Pharm. Res. 20,6 (2003), pp. 873-878.

[30] C. Wu and J.W. McGinity, Non-traditional plasticization of polymeric films, Int. J. Pharm. 177 (1999), pp. 15-27.

[31] J. Siepmann, F. Lecomte and R. Bodmeier, Diffusion-controlled drug delivery systems: calculation of the required composition to achieve desired release profiles, J. Controlled Release 60,2-3 (1999), pp. 379-389.

[32] H. Rey, K.G. Wagner, P. Wehrle and P.C. Schmidt, Development of Matrix-Based Theophylline Sustained-Release Microtablets, Drug Dev. Ind. Pharm. 26,1 (2000), pp. 21-26.

[33] S. Narisawa, M. Nagata, C. Danyoshi, H. Yoshino, K. Murata, Y. Hirakawa and K. Noda, An organic acid-induced sigmoidal release system for oral controlled-release preparations, Pharm. Res. 11,1 (1994), pp. 111-116.

[34] M. Kidokoro, N.H. Sha, A.W. Malick, M.H. Infeld and J.W. McGinity, Properties of Tablets Containing Granulations of Ibuprofen and an Acrylic Copolymer Prepared by Thermal Processes, Pharm. Dev. Technol. 6,2 (2001), pp. 263-275.

[35] N. Follonier, E. Doelke and E.T. Cole, Evaluation of hot-melt extrusion as a new technique for the production of polymer-based pellets for sustained release capsules containing high loadings of freely soluble drugs, Drug Dev. Ind. Pharm. 20,8 (1994), pp. 1323-1339.

[36] Y. Zhu, N.H. Shah, A.W. Malick, M.H. Infeld and J.W. McGinity, Influence of a lipophilic thermal lubricant on the processing conditions and drug release properties of chlorpheniramine maleate tablets prepared by hot-melt extrusion, J. Drug Del. Sci. Technol. 14,4 (2004), pp. 313-318.

[37] H.C. Andersen, Molecular dynamics simulations at constant pressure and/or temperature. J. Chem. Phys. 72,4 (1980), pp. 2384-2393. 
[38] M.J. Hwang, T.P. Stockfisch and A.T. Hagler, Derivation of Class II Force Fields. 2. Derivation and Characterization of a Class II Force Field, CFF93, for the Alkyl Functional Group and Alkane Molecules, J. Am. Chem. Soc. 116,6 (1994), pp. 25152525 .

[39] H. Sun, Ab initio calculations and force field development for computer simulation of polysilanes, Macromolecules 28,3 (1995), pp. 701-712.

[40] H. Sun, COMPASS: An ab Initio Force-Field Optimized for Condensed-Phase Applications-Overview with Details on Alkane and Benzene Compounds, J. Phys. Chem. B 102,38 (1998), pp. 7338-7364.

[41] S.W. Bunte and H. Sun, Molecular Modeling of Energetic Materials: The Parameterization and Validation of Nitrate Esters in the COMPASS Force Field, J. Phys. Chem. B. 104,11 (2000), pp. 2477-2489.

[42] Y. Zhu, N.H. Shah, A.W. Malick, M.H. Infeld and J.W. McGinity, Influence of thermal Processing on the Properties of chlorpheniramine Maleate Tablets Containing an Acrylic Polymer, Pharm. Dev. Technol. 7,4 (2002), pp. 481-489 .

[43] N. Schuld and B.A. Wolf, Polymer-Solvent Interaction Parameters, in J. Brandrup, E.H. Immergut and E.A. Grulke (eds.), Polymer Handbook, John Wiley \& Sons Inc., New York, 1999, pp. 675-688.

[44] T.A. Kavassalis, P. Choi and A. Rudin, Molecular models and three dimensional solubility parameters of non-ionic surfactants, in K.E. Gubbins and N. Quirke (eds.), Molecular Simulation and Industrial Applications, Gordon \& Breach, Amsterdam, 1996, pp. 315-329.

[45] C. Wu and J.W. McGinity, Influence of methylparaben as a solid-state plasticizer on the physicochemical properties of Eudragit RS PO hot-melt extrudates, Europ. J. Pharm. Biopharm. 56 (2003), pp. 95-100.

[46] R. Chang and C. Hsiao, Eudragit RL and RS pseudolatices: properties and performance in pharmaceutical coating as a controlled release membrane for theophylline pellets, Drug Dev. Ind. Pharm. 15,2 (1989), pp. 187-196.

[47] J.C. Gutiérrez-Rocca and J.W. McGinity, Influence of water soluble and insoluble plasticizers on the physical and mechanical properties of acrylic resin copolymers, Int. J Pharm. 103,3 (1994), pp. 293-301.

[48] L.H. Sperling, Introduction to Physical Polymer Science, John Wiley \& Sons, Inc., New York, 2001, pp.73-75. 


\section{Page 19 of 31}

[49] L.H. Sperling, Introduction to Physical Polymer Science, John Wiley \& Sons, Inc., New York, 2001, pp.70-75.

2

3

4

5

6

7

8

9

10

11

12

13

14

15

16

17

18

19

20

21

22

23

24

25

26

27

28

29

30

31

32

33

34

35

36

37

38

39

40

41

42

43

44

45

46

47

48

49

50

51

52

53

54

55

56

57

58

59

60 


\section{Tables}

Table 1. Overview of densities, molar volumes, and solubility parameters calculated via MD simulations.

\begin{tabular}{c|cc|ccc} 
& $\begin{array}{c}\rho \\
{\left[\mathrm{g} / \mathrm{cm}^{3}\right]}\end{array}$ & $\begin{array}{c}v_{\mathrm{M}} \\
{\left[\mathrm{cm}^{3}\right]}\end{array}$ & $\begin{array}{c}\delta \\
{\left[\left(\mathrm{J} / \mathrm{cm}^{3}\right)^{0.5}\right]}\end{array}$ & $\begin{array}{c}\delta_{\mathrm{e}} \\
{\left[\left(\mathrm{J} / \mathrm{cm}^{3}\right)^{0.5}\right]}\end{array}$ & $\begin{array}{c}\delta_{\mathrm{d}} \\
{\left[\left(\mathrm{J} / \mathrm{cm}^{3}\right)^{0.5}\right]}\end{array}$ \\
\hline TEC & 1.114 & 248.6 & 20.70 & 8.62 & 18.81 \\
ATBC & 1.039 & 387.5 & 17.96 & 4.57 & 17.37 \\
DBS & 0.910 & 345.4 & 17.63 & 3.29 & 17.32 \\
IBU amorph. & 0.977 & 211.2 & 20.95 & 11.89 & 17.25 \\
IBU cryst. & 1.092 & 188.9 & 31.64 & 26.53 & 17.23 \\
THEO amorph. & 1.350 & 133.5 & 29.48 & 16.99 & 24.10 \\
THEO cryst. & 1.493 & 120.7 & 51.43 & 45.85 & 23.29 \\
ERS & 1.028 & 6250.1 & 17.34 & 11.32 & 13.13
\end{tabular}

$\rho\left[\mathrm{g} / \mathrm{cm}^{3}\right]=$ density

$\nu_{\mathrm{M}}\left[\mathrm{cm}^{3}\right]=$ molar volume

$\delta\left[\left(\mathrm{J} / \mathrm{cm}^{3}\right)^{0.5}\right]=$ overall Hildebrand solubility parameter

$\delta_{\mathrm{e}}\left[\left(\mathrm{J} / \mathrm{cm}^{3}\right)^{0.5}\right]=$ solubility parameter representing the electrostatic interactions, according to Equation 4 .

$\delta_{\mathrm{d}}\left[\left(\mathrm{J} / \mathrm{cm}^{3}\right)^{0.5}\right]=$ solubility parameter representing the dispersive interactions, according to Hansen

Table 2. Calculated Flory Huggins parameter $\chi$ and free enthalpy of mixing $\Delta G_{\mathrm{m}}$ of $10 \%$ excipient with $90 \%$ polymer at $298 \mathrm{~K}$.

\begin{tabular}{c|cccc|ccc} 
& TEC & ATBC & DBS & $\begin{array}{c}\text { IBU } \\
\text { amorph. }\end{array}$ & $\begin{array}{c}\text { IBU } \\
\text { crystal. }\end{array}$ & $\begin{array}{c}\text { THEO } \\
\text { amorph. }\end{array}$ & $\begin{array}{c}\text { THEO } \\
\text { cryst. }\end{array}$ \\
\hline$\chi$ & 1.132 & 0.060 & 0.012 & 1.111 & 15.582 & 7.939 & 56.584 \\
$\Delta G_{\mathrm{m}}\left[\mathrm{J} / \mathrm{cm}^{3}\right]$ & -1.318 & -1.476 & -1.682 & -1.566 & 15.343 & 9.965 & 99.846
\end{tabular}

Table 3. Overview of extrapolated experimental and calculated $T_{\mathrm{g}}$ values in Kelvin of the different polymer/plasticizer systems with $n$ symbolizing the number of plasticizer molecules per simulation box.

\begin{tabular}{c|cc|cc|cc|cc|cc}
\multirow{2}{n}{} & \multicolumn{2}{|c|}{ ERS } & \multicolumn{2}{|c|}{ TEC } & \multicolumn{2}{|c|}{ IBU } & \multicolumn{2}{c|}{ DBS } & \multicolumn{2}{|c}{ ATBC } \\
& DSC & MD & DSC & MD & DSC & MD & DSC & MD & DSC & MD \\
\hline 0 & 336.7 & 354 & & & & & & & & \\
6 & & & 320.2 & 332 & 328.5 & 349 & 315.9 & 348 & 316.3 & 353 \\
12 & & & 306.5 & 308 & & & & & &
\end{tabular}




\section{Page 21 of 31}

Table 4. Composition and experimental Tg values of all samples produced by hot melt extrusion

\begin{tabular}{ccccc|cc} 
polymer & TEC & ATBC & DBS & IBU & $T_{\mathrm{g}}[\mathrm{K}]$ & $\begin{array}{c}\text { standard } \\
\text { deviation }\end{array}$ \\
\hline $100 \%$ & & & & & 336.7 & 0.6 \\
\hline $89 \%$ & $11 \%$ & & & & 305.3 & 0.9 \\
$85 \%$ & $15 \%$ & & & & 300.9 & 1.2 \\
$78 \%$ & $22 \%$ & & & & 280.4 & 1.1 \\
\hline $90 \%$ & & $10 \%$ & & & 310.0 & 0.6 \\
$86 \%$ & & $14 \%$ & & & 303.9 & 1.4 \\
$79 \%$ & & $21 \%$ & & & 289.7 & 0.9 \\
\hline $91 \%$ & & & $9 \%$ & & 304.6 & 0.5 \\
$85 \%$ & & & $15 \%$ & & 296.1 & 0.5 \\
$81 \%$ & & $19 \%$ & & 285.0 & 1.7 \\
\hline $90 \%$ & & & $10 \%$ & 318.5 & 0.3 \\
$80 \%$ & & & $20 \%$ & 300.5 & 0.9
\end{tabular}




\section{Figure captions}

Figure 1. Visualization of Eudragit ${ }^{\circledR}$ RS polymer chain consisting of 64 monomers and all other molecules (both plasticizers and drugs) used in this study. The chlorine anion is depicted larger for better visibility, the different grades of grey in this and the following figures correspond to different atom types with white reserved for hydrogen, light grey oxygen, grey carbon, and black nitrogen or chlorine. All the graphical displays of molecules were generated with the Materials Visualizer (from Accelrys Inc.).

Figure 2. Simulation box $(3.7 \times 3.7 \times 3.7 \mathrm{~nm})$ with periodic boundaries showing 4 Eudragit ${ }^{\circledR} \mathrm{RS}$ polymer chains and 6 ibuprofen molecules after a relaxation time of $2 \mathrm{~ns}$ at $430 \mathrm{~K}$. One polymer chain and all ibuprofen molecules are visualized in ball and stick style to demonstrate the size of the box as well as the distribution of the drug molecules.

Figure 3. Visualization of the dispersive $\delta_{\mathrm{d}}$ (right side, black) and the electrostatic $\delta_{\mathrm{e}}$ (left side, grey) solubility parameters according to Hansen with the upright dashed lines marking the values of the pure Eudragit ${ }^{\circledR}$ RS polymer.

Figure 4. Plot of the computed specific volume $v$ of pure Eudragit ${ }^{\circledR}$ RS polymer (a), Eudragit ${ }^{\circledR}$ RS polymer and 6 TEC (b) as well as 12 TEC (c) molecules per simulation box vs. temperature $T$ of the system. The intersection point of the two lines resulting from a linear regression of the data points corresponding to the glassy ( $\boldsymbol{\square}$ ) and the rubbery ( $\square$ ) state determines the simulated $T_{\mathrm{g}}$ values (see Table 3 ). All values are mean values of the specific volumes at the specified temperature of at least three independent systems, printed error bars represent the standard deviation, circles represent values not used in the analysis.

Figure 5. Comparison of the dependence of the glass transition temperature $T_{\mathrm{g}}$ on the TEC weight proportion $w_{\text {TEC }}$ determined by the new MD model (full symbols, dashed line), the MD model used in our previous communication (open symbols, dotted line), and experimental (full line) DSC values. All lines result from a linear regression of the data points.

Figure 6. Plot of the computed specific volume $v$ vs. temperature $T$ of three different polymer-plasticizer systems, each containing 4 polymer chains and 6 ATBC (a), 6 DBS (b), and 6 ibuprofen (c) molecules per simulation box. Symbols and determination of $T_{\mathrm{g}}$ as in Figure 4 (values can be found in Table 3).

Figure 7. Plot of the heat flow against temperature $T$ in a DSC experiment of a pure polymer (full line) as well as a polymer-TEC mixture (dashed line) with $w=17 \%$. Both show a distinct step in the heat flow, marked by the 


\section{Page 23 of 31}

1

2

3

4

5

6

7

8

9

10

11

12

13

14

15

16

17

18

19

20

21

22

23

24

25

26

27

28

29

30

31

32

33

34

35

36

37

38

39

40

41

42

43

44

45

46

47

48

49

50

51

52

53

54

55

56

57

58

59

60

onset/endset point with the middle between these two points yielding the experimental value of the glass transition temperature $T_{\mathrm{g}}$.

Figure 8. Plot of the heat flow against temperature $T$ in a DSC experiment of a polymer-DBS mixture (full line) with $w=21.5 \%$ as well as of pure DBS (dashed line). The melting peak of DBS is also visible in the polymerDBS curve thus indicating the existence of two different phases. 


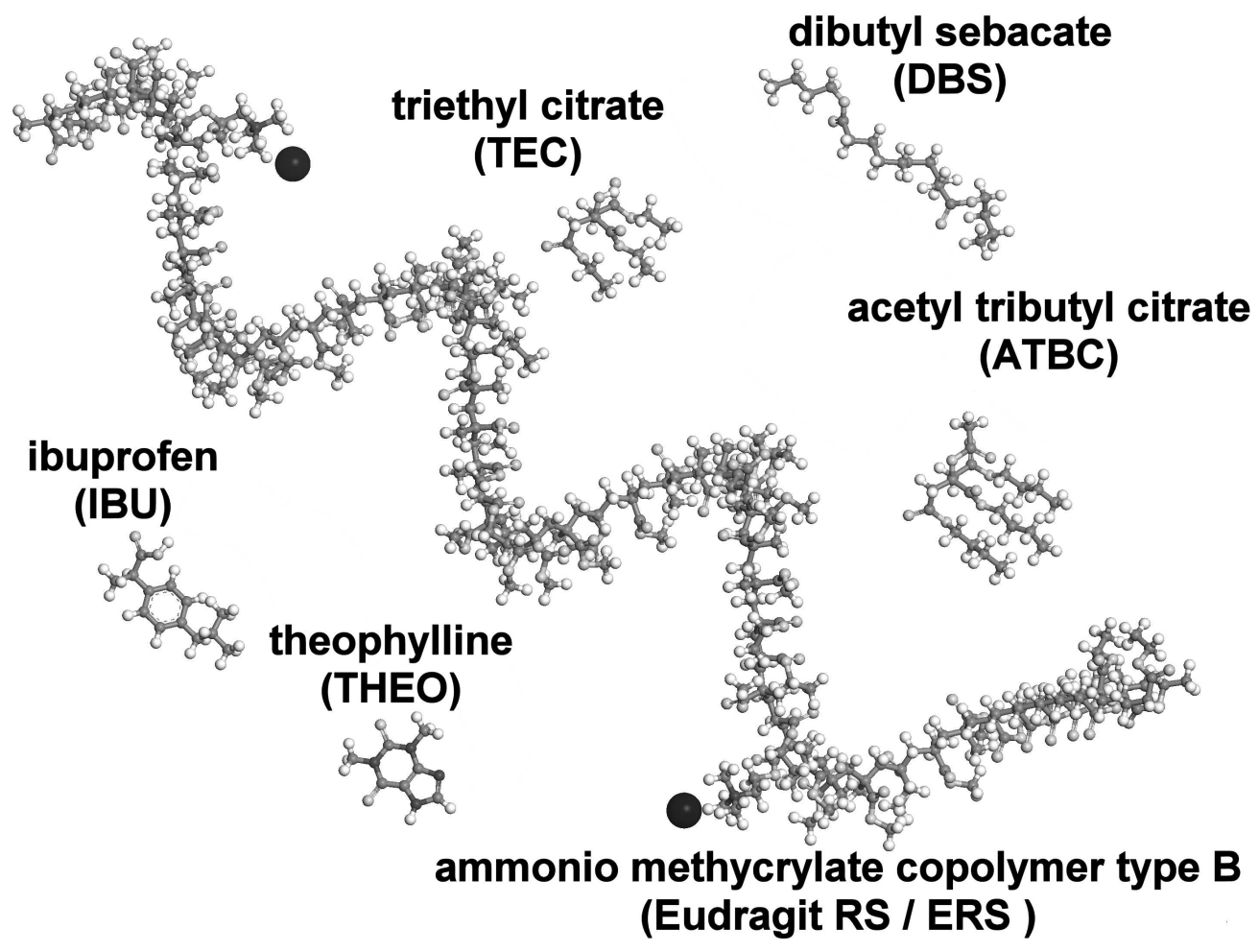

Figure 1. Visualization of Eudragit $\AA$ RS polymer chain consisting of 64 monomers and all other molecules (both plasticizers and drugs) used in this study. The chlorine anion is depicted larger for better visibility, the different grades of grey in this and the following figures correspond to different atom types with white reserved for hydrogen, light grey oxygen, grey carbon, and black nitrogen or chlorine. All the graphical displays of molecules were generated with the Materials Visualizer (from Accelrys Inc.).

$159 \times 119 \mathrm{~mm}(460 \times 460 \mathrm{DPI})$ 


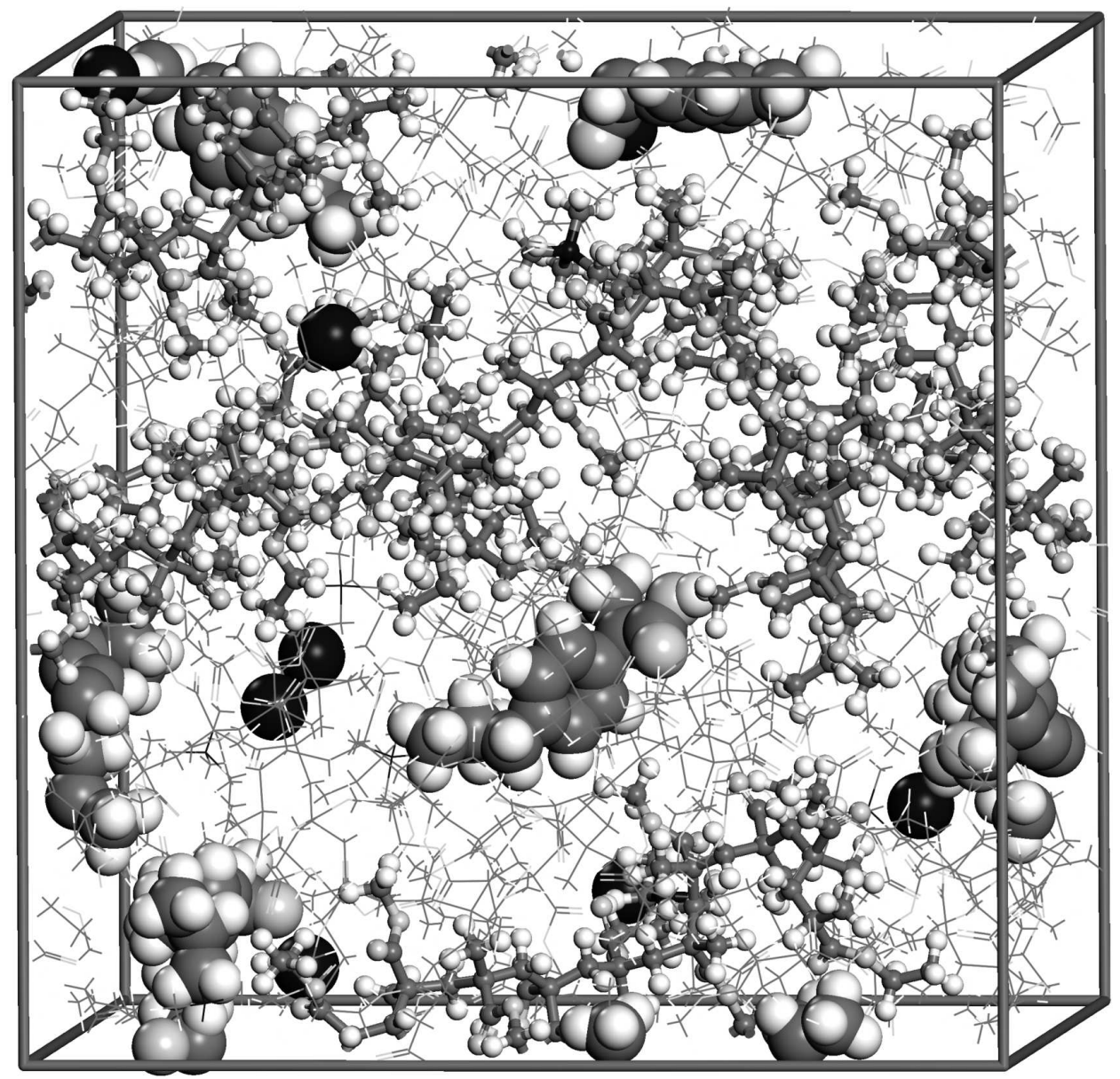

Figure 2. Simulation box $(3.7 \times 3.7 \times 3.7 \mathrm{~nm})$ with periodic boundaries showing 4 Eudragit $\circledast R S$ polymer chains and 6 ibuprofen molecules after a relaxation time of $2 \mathrm{~ns}$ at $430 \mathrm{~K}$. One polymer chain and all ibuprofen molecules are visualized in ball and stick style to demonstrate the size of the box as well as the distribution of the drug molecules. $75 \times 71 \mathrm{~mm}(600 \times 600 \mathrm{DPI})$ 


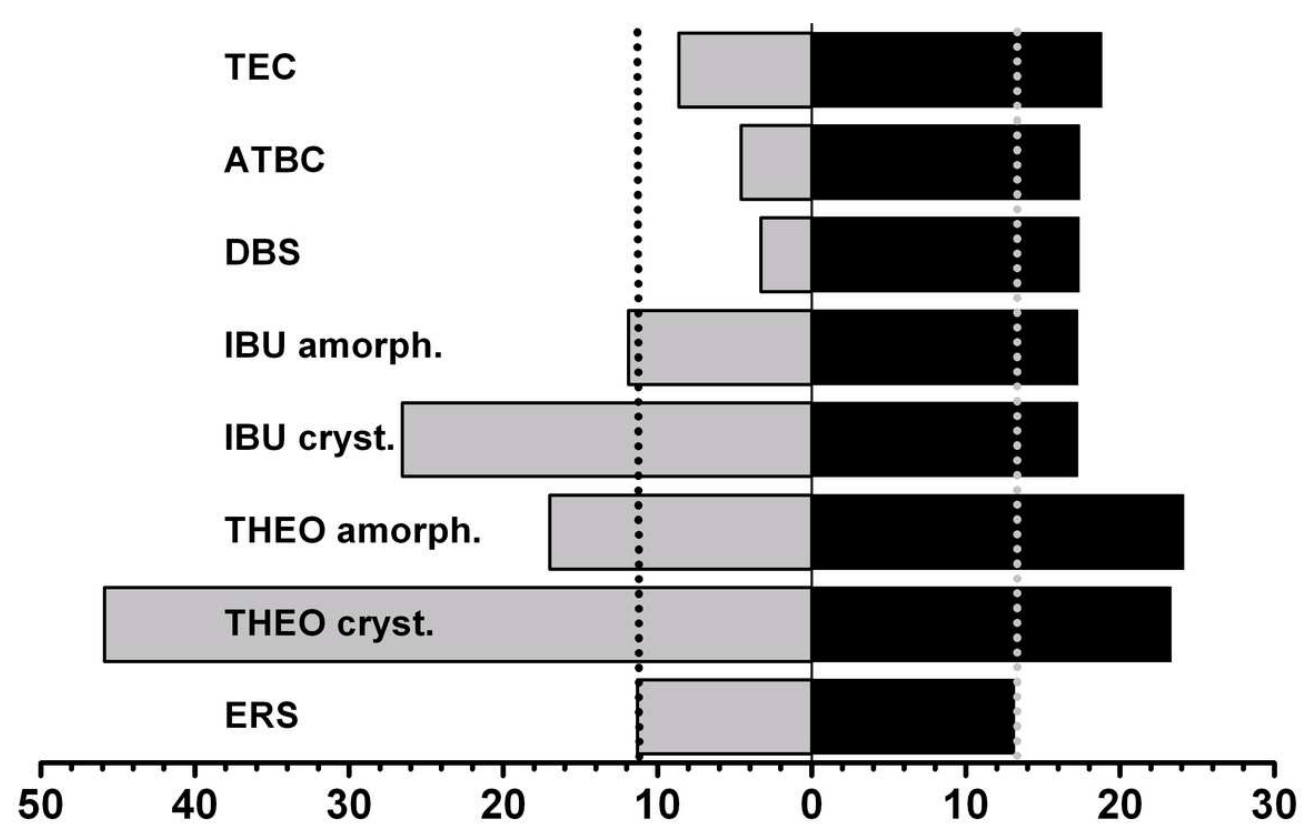

Figure 3. Visualization of the dispersive $\delta \mathrm{d}$ (right side, black) and the electrostatic $\delta e$ (left side, grey) solubility parameters according to Hansen with the upright dashed lines marking the values of the pure Eudragit ${ }^{\circledR}$ RS polymer. $49 \times 30 \mathrm{~mm}(600 \times 600 \mathrm{DPI})$ 

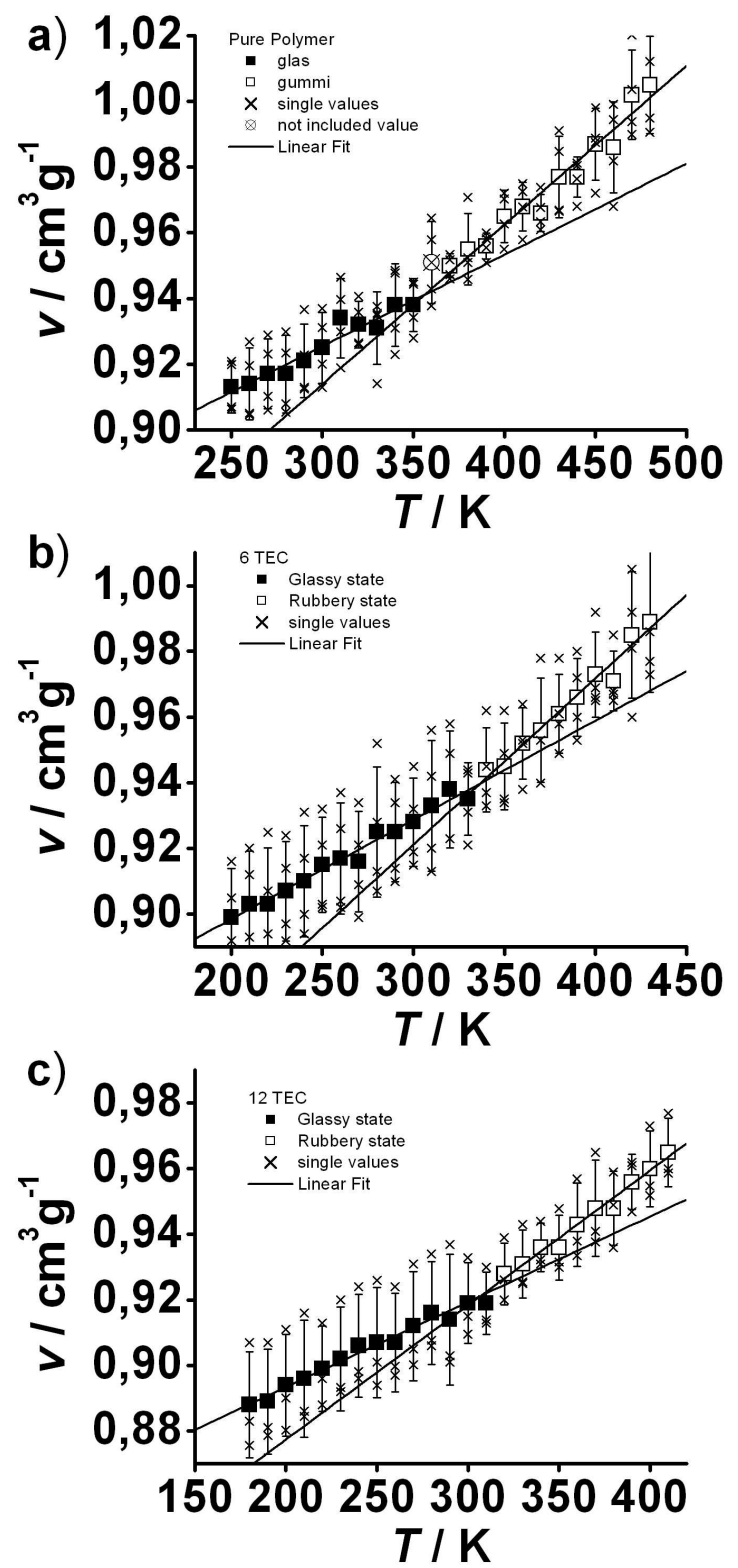

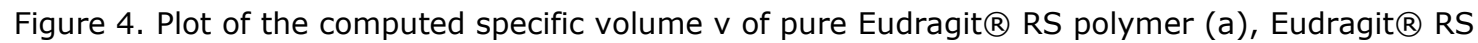
polymer and 6 TEC (b) as well as 12 TEC (c) molecules per simulation box vs. temperature T of the system. The intersection point of the two lines resulting from a linear regression of the data points corresponding to the glassy ( $\mathbf{a})$ and the rubbery ( $\square$ ) state determines the simulated Tg values (see Table 3). All values are mean values of the specific volumes at the specified temperature of at least three independent systems, printed error bars represent the standard deviation, circles represent values not used in the analysis. $80 \times 171 \mathrm{~mm}(439 \times 439 \mathrm{DPI})$ 


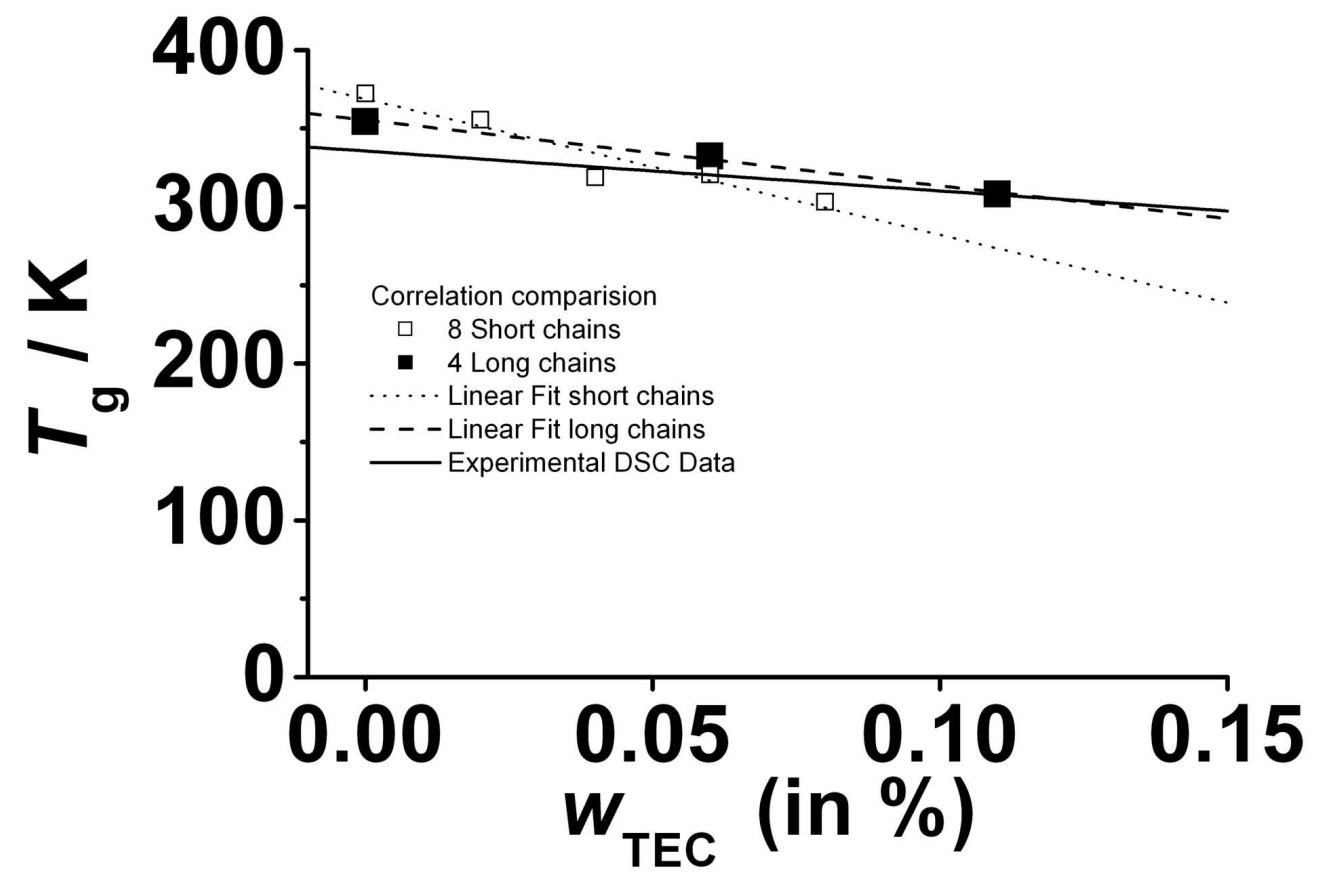

Figure 5. Comparison of the dependence of the glass transition temperature Tg on the TEC weight proportion wTEC determined by the new MD model (full symbols, dashed line), the MD model used in our previous communication (open symbols, dotted line), and experimental (full line) DSC values. All lines result from a linear regression of the data points.

\section{$81 \times 55 \mathrm{~mm}(600 \times 600 \mathrm{DPI})$}



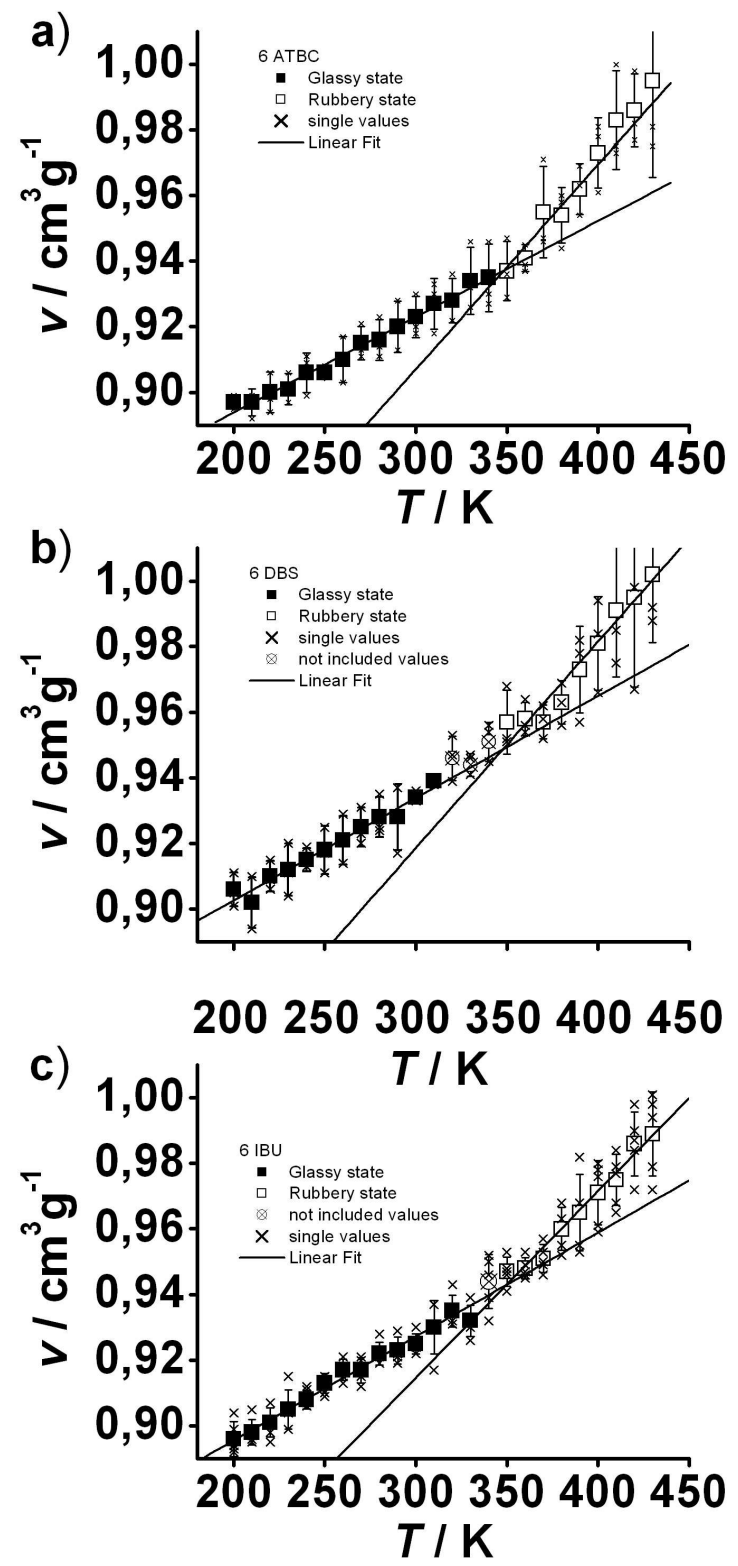

Figure 6. Plot of the computed specific volume $v$ vs. temperature $T$ of three different polymerplasticizer systems, each containing 4 polymer chains and 6 ATBC (a), 6 DBS (b), and 6 ibuprofen (c) molecules per simulation box. Symbols and determination of Tg as in Figure 4 (values can be found in Table 3 ).

$79 \times 174 \mathrm{~mm}(430 \times 430 \mathrm{DPI})$ 


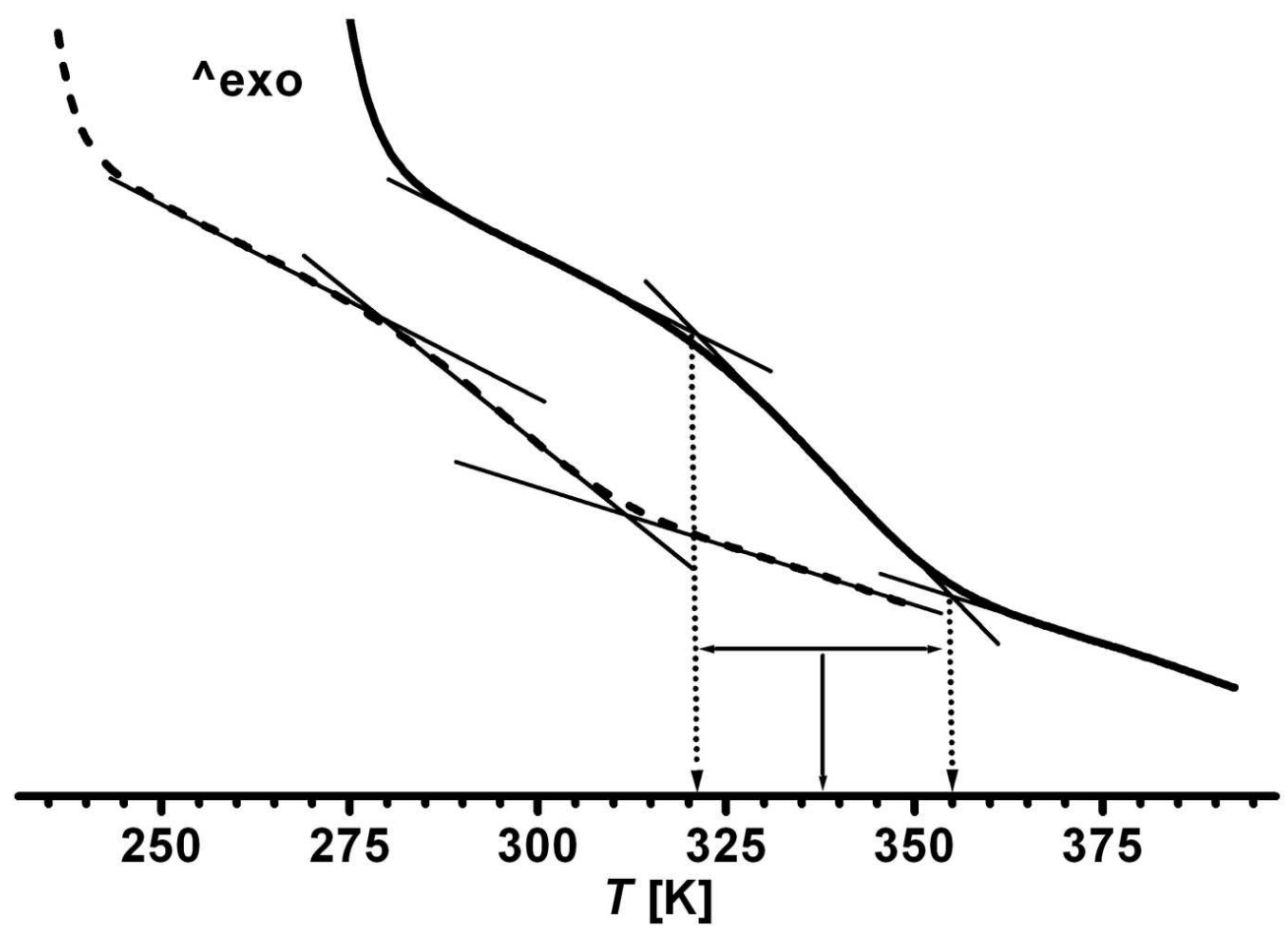

Figure 7. Plot of the heat flow against temperature T in a DSC experiment of a pure polymer (full line) as well as a polymer-TEC mixture (dashed line) with $w=17 \%$. Both show a distinct step in the heat flow, marked by the onset/endset point with the middle between these two points yielding the experimental value of the glass transition temperature $\mathrm{Tg}$. $57 \times 41 \mathrm{~mm}(600 \times 600 \mathrm{DPI})$ 
Figure 8. Plot of the heat flow against temperature T in a DSC experiment of a polymer-DBS mixture (full line) with $\mathrm{w}=21.5 \%$ as well as of pure DBS (dashed line). The melting peak of DBS is also visible in the polymer-DBS curve thus indicating the existence of two different phases. $60 \times 45 \mathrm{~mm}(600 \times 600 \mathrm{DPI})$ 